\title{
Diferencial de salários entre homens e mulheres segundo a condição de migração
}

\author{
Natalia Nunes Ferreira Batista* \\ Maria Cristina Cacciamali**
}

\begin{abstract}
Este trabalho analisa a diferença salarial por sexo, segundo a condição de migração da população. Por meio do cálculo do índice de dissimilaridade de Duncan e da decomposição de Oaxaca para os salários de homens e mulheres migrantes e não-migrantes, encontraram-se situações diferenciadas para a Região Sudeste e o restante do país. Os resultados mostram que a elevada diferença salarial entre sexo verificada na população migrante residente fora da Região Sudeste mantém-se devido à diferente valorização no mercado de trabalho do local de destino dos atributos masculinos vis-à-vis os femininos. Já no caso do Sudeste, a menor diferença salarial constatada entre homens e mulheres migrantes deve-se mais às características específicas das trabalhadoras do que à valorização diferenciada no mercado de trabalho.
\end{abstract}

Palavras-chave: Diferencial de salário por sexo. Migração. Segregação. Índice de dissimilaridade. Decomposição Oaxaca-Blinder.

\section{Introdução}

O aumento da participação da mulher como provedora da renda familiar deu um grande salto a partir dos anos 1970. Geralmente a inserção feminina no mercado de trabalho não diminui o papel da mulher como mãe, esposa e responsável pela administração do lar. Justamente devido aos diversos papéis desempenhados na sociedade pela mulher, a decisão de participar do mercado de trabalho acaba sendo mais complexa do que a masculina.

Dependendo do período abordado nos trabalhos empíricos, os principiais determi- nantes da crescente presença da mulher na força de trabalho variam em importância entre queda da fecundidade, proporção de mulheres como chefes de família (LEME; WAJNMAN, 1999), ${ }^{1}$ situação conjugal e idade (SCORZAFAVE; MENEZES-FILHO, 2001). ${ }^{2}$ A única variável comum que apresenta grande relevância em todos os trabalhos da área diz respeito ao aumento da escolaridade. ${ }^{3}$

No entanto, mesmo com maior nível médio de instrução, uma vez inserida no mercado de trabalho, a mulher apresenta uma média salarial inferior à masculina. Mesmo com a redução da diferença salarial entre

\footnotetext{
* Economista, professora doutora do Departamento de Economia da Faculdade de Administração, Economia e Contabilidade - USP Ribeirão Preto (Fearp).

** Economista, professora titular do Departamento de Economia da Faculdade de Administração, Economia e Contabilidade - USP (FEA).

${ }^{1}$ As autoras utilizaram dados da PNAD de 1977 a 1997.

2 Os autores utilizaram dados da PNAD e da PME entre 1982 e 1997.

${ }^{3}$ Matos e Machado (2006) mostram que a partir de 1979 as mulheres apresentam sistematicamente mais anos de estudo em relação aos homens.
} 
homens e mulheres observada nos últimos anos, o primeiro grupo ganha, em média, $60 \%$ a mais do que o segundo (MACHADO; OLIVEIRA; WAJNMAN, 2005).

Apesar de a lista de trabalhos que analisam o diferencial de rendimento segundo gênero ser extensa, ${ }^{4}$ existe uma lacuna na abordagem deste tema no contexto migratório. Haveria razões para que a diferença de rendimentos entre homens e mulheres seja distinta entre a população migrante e a não-migrante?

A migração traz a necessidade de inserção em um mercado de trabalho no local de destino, onde os atributos pessoais e produtivos podem ter valores distintos daqueles verificados no local de origem. A existência de grandes distinções na estrutura ocupacional entre as regiões pode fazer com que homens e mulheres migrantes tenham acesso diferenciado ao mercado de trabalho local, quando comparados à população não-migrante.

Paralelamente à diversidade dos mercados de trabalho regionais, tem-se que a motivação do deslocamento também é bastante distinta entre os sexos. Utilizando dados da PNAD de 2001, Oliveira e Jannuzzi (2004) mostram que, enquanto a busca por trabalho corresponde à motivação predominante para migração dos homens, no caso feminino o principal fator é a necessidade de acompanhar a família. Esta diferenciação não só interfere na decisão de trabalhar uma vez instalada no local de destino, como também influencia na magnitude do salário reserva de homens e mulheres migrantes.

A análise da migração feminina para os Estados de São Paulo, Rio de Janeiro e Pernambuco, realizada por Chaves (2004), ${ }^{5}$ mostra que grande parte das mulheres que migram solteiras também se insere no contexto de migração familiar, uma vez que se desloca junto com o chefe do domicílio.
Nem sempre as mulheres que migram acompanhadas, ou ainda que se deslocam por motivos diferentes aos relacionados ao trabalho, direcionam-se a destinos onde seus atributos serão mais bem avaliados pelo mercado. Assim, as especificidades da migração feminina trazem elementos adicionais à questão da diferença salarial entre homens e mulheres.

Dados da PNAD de 2005 apontam que, de modo geral, a discrepância entre os rendimentos de homens e mulheres é maior entre os migrantes ${ }^{6}$ do que entre os não-migrantes. ${ }^{7}$ A Região Sudeste é exceção, já que nos Estados de São Paulo, Rio de Janeiro e Minas Gerais a maior diferença entre rendimentos de homens e mulheres ocorre na população não-migrante.

Para analisar o diferencial de salários entre homens e mulheres segundo sua condição de migração, este trabalho conta com mais cinco seções, além desta introdução. A seguir, é apresentada uma breve revisão da literatura referente ao diferencial de salário segundo o sexo no Brasil. Posteriormente, relaciona-se o tema da diferença de rendimentos com o processo migratório, separando os dados da discrepância salarial por sexo segundo a condição de migração para as cinco grandes regiões do país. São mostrados, ainda, os resultados empíricos da decomposição da diferença salarial, bem como o indicador de segregação do mercado de trabalho para homens e mulheres e para migrantes e não-migrantes. $\mathrm{O}$ artigo finaliza com as considerações finais.

\section{Literatura diferencial de salário: discriminação e segregação ocupacional}

Entre 1970 e 1990, a população economicamente ativa (PEA) feminina cresceu $260 \%$, contra apenas $73 \%$ da masculina

\footnotetext{
${ }^{4}$ Alves et al. (1997), Barros et al. (2000), Bruschini (2000), Oliveira (1998), Ometto et al. (1999), entre outros.

5 A autora utiliza informações sobre o estado conjugal ao migrar presente no Censo Demográfico de 1991.

6 Neste trabalho migrante corresponde aos indivíduos que residem em uma Unidade da Federação distinta daquela de seu nascimento, independente do tempo de residência.

${ }^{7} \mathrm{Na}$ área urbana as mulheres não-migrantes ganham em média 22,3\% a menos que os homens não-migrantes. Já entre a população migrante esta discrepância é de 33,5\% em detrimento da mulher (amostra de pessoas acima de 24 anos).
} 
(ARAÚJO; RIBEIRO, 2002). Apesar da queda significativa verificada no diferencial de salário durante a primeira metade da década de 1990,8 os dados da PNAD de 2005 indicam uma discrepância de aproximadamente $20 \%$ em favor dos homens.

Em linhas gerais, a desigualdade de salários pode ser decorrente de dois fatores: a heterogeneidade dos trabalhadores com respeito aos seus atributos produtivos; e o fato de trabalhadores com idêntica qualificação serem remunerados de forma distinta, seja porque são discriminados (tratamento diferenciado baseado em atributos nãoprodutivos), seja porque o mercado de trabalho é segmentado - caso em que os postos de trabalho valorizam os atributos do trabalhador de forma diferente.

A possibilidade de agrupar os trabalhos empíricos sobre diferencial de salários entre os sexos em duas categorias distintas reflete o embate teórico existente na literatura sobre o tema. Na primeira categoria encontram-se os trabalhos que enfocam o papel da discriminação na explicação deste diferencial (tem como base a Teoria do Capital Humano) ${ }^{9}$ e, na segunda, estão aqueles que privilegiam os modelos de segmentação, indicando a existência de barreiras ocupacionais segundo o sexo. 10

Na literatura nacional, a importância da segmentação ocupacional na explicação do diferencial de salário entre os sexos ainda é controversa. Autores como Soares e Oliveira (2004) e Oliveira (1998) utilizam indicadores de segregação, ou ainda avaliação da proporção de mulheres em grupos distintos de ocupações para mostrar que a segmentação ocupacional responde por uma parcela grande do diferencial salarial entre homens e mulheres.
Geralmente, os autores que sustentam a relevância da segregação ocupacional na contribuição para a manutenção do diferencial de salário entre homens e mulheres argumentam que, apesar dos avanços observados na década de 1990 , as mulheres ainda têm uma inserção ocupacional mais estreita, concentrando-se no setor de serviços (especialmente os domésticos), em atividades de escritório e nas áreas públicas de saúde, educação e administração pública. ${ }^{11}$ Dessa maneira, o aumento da taxa de atividade das mulheres pode até ter contribuído para uma maior diversificação no mercado de trabalho, mas, para esses autores, isso não refletiu uma desconcentração do trabaIho feminino das atividades tradicionalmente exercidas pelas mulheres.

Por outro lado, o trabalho de Barros et al. (1995) utiliza a técnica de decomposição não paramétrica e conclui que, apesar da existência de uma estrutura ocupacional bastante diferenciada entre homens e mulheres, praticamente a totalidade da diferença salarial observada entre estes dois grupos deve-se à discriminação. ${ }^{12}$ Os autores argumentam que a simples ocorrência de uma alocação diferenciada de homens e mulheres entre as ocupações não caracteriza a segregação ocupacional por sexo, ${ }^{13}$ já que os dois grupos podem estar inseridos em ocupações diferentes, mas que possuem níveis de renda similares.

Araújo e Ribeiro (2002), por meio de dados da PNAD de 1995, atualizam o trabaIho de Barros et al. (1995), incorporando a abertura por região. Os resultados reafirmam que a discriminação salarial verificada entre homens e mulheres é intraocupacional e que as maiores taxas são encontradas nas Regiões Sul e Sudeste. Os autores também

\footnotetext{
${ }^{8}$ Em 1990 o rendimento do trabalho médio feminino correspondia a 57\% do masculino e em cinco anos esta diferença caiu para $41 \%$.

${ }^{9}$ Existem centenas de trabalhos empíricos embasados neste referencial teórico, mas os pioneiros foram Blinder (1973) e Oaxaca (1973).

10 Neste caso, o papel das diferenças observadas na estruturas ocupacionais masculina e feminina ganha destaque na explicação dos diferencias de salário entre os sexos.

11 Sobre o processo de feminização no mercado de trabalho, consultar Kon (1999) e Soares (2001).

12 Os autores utilizam dados da PNAD para a década de 1980 (1981-1989).

13 Os autores utilizam o termo "discriminação alocativa" para indicar a distribuição diferenciada de homens e mulheres na estrutura ocupacional.
} 
constataram que a "discriminação ocupacional" está presente em todas as regiões, mas esta se mostrou favorável às mulheres, pois contribuiu para a redução da diferença salarial.

Seguindo a metodologia proposta por Brown et al. (1980), que introduz o papel da segmentação ocupacional à tradicional decomposição de Oaxaca e Blinder, o trabalho de Ometto et al. (1999) analisa os mercados de trabalho dos Estados de Pernambuco e São Paulo. ${ }^{14}$ Os resultados mostram que a segregação ocupacional entre homens e mulheres está presente apenas em São Paulo, mas que a discriminação intraocupacional ocorre nos dois estados.

Uma parte da dificuldade da verificação da existência ou não da segregação ocupacional entre homens e mulheres deve-se a aspectos metodológicos que envolvem a aplicação dos índices escolhidos. Resumidamente, a escolha da população base e a classificação ocupacional são os principais pontos metodológicos determinantes dos resultados.

A escolha da população base afeta os resultados das análises ao nível nacional, pois pode haver uma variação na composição ocupacional e na razão de sexo em cada população, com efeitos não desprezíveis nos resultados. Já o nível de detalhamento da classificação ocupacional escolhida para a análise também é determinante dos valores obtidos para os índices de segregação, pois, como as medidas, são sensíveis ao número de categorias utilizadas; há uma tendência de que, quanto mais agregados os grupos ocupacionais, menor o grau de segregação ocupacional verificado.

Com relação aos trabalhos citados anteriormente, enquanto os de Barros et al. (1995), Araújo e Ribeiro (2002) e Oliveira (1998) utilizam a estrutura ocupacional presente na PNAD, o de Ometto et al. (1999) constrói, a partir das categorias desagre- gadas, cinco agrupamentos ocupacionais, tendo como base a proporção feminina em cada uma delas. Assim, ao mesmo tempo em que a utilização de uma estrutura ocupacional já agrupada (no caso da PNAD) facilita a comparação entre os índices obtidos em diversos trabalhos, o estreito leque de categorias ocupacionais pode obscurecer a segmentação ocupacional.

O índice de segregação mais utilizado na literatura é o índice de dissimilaridade de Duncan \& Duncan (D)..$^{15}$ Este indicador da segregação ocupacional por sexo é interpretado como a proporção de mulheres ou homens que teriam que trocar de ocupações para que a razão de sexo de cada ocupação fosse igual à razão de sexo do total da força de trabalho, ou seja, para eliminar a segregação ocupacional. Os valores assumidos pelo índice de dissimilaridade $\mathrm{D}$ variam de 0 , quando não há diferença nas distribuições ocupacionais de homens e mulheres, até 100 , na presença de uma segregação completa.

\section{Migração e diferença salarial entre homens e mulheres}

Antes de serem abordadas as principais questões existentes referentes à diferença salarial segundo o sexo e a migração, faz-se necessário explicitar o conceito de migrante que é utilizado neste trabalho. Segundo recomendações das Nações Unidas, ${ }^{16}$ a conceituação de migração requer um recorte espacial e temporal.

No entanto, devido aos objetivos do trabalho, utilizou-se apenas o recorte espacial para diferenciar a população migrante da não-migrante, ou seja, o estado de nascimento (migrantes acumulados). Dessa forma, a pessoa que, em 2005, residia em uma Unidade da Federação distinta daquela onde nasceu foi considerada migrante. Com isso, aproximadamente $82 \%$ da população

\footnotetext{
${ }^{14}$ A autora utiliza dados da PNAD de 1981 a 1990, excluindo-se os anos de 1982 e 1986.

15 Apesar de apresentar problemas para a comparação de populações ao longo do tempo (não capta mudanças na estrutura ocupacional), o fato de ser invariante sob transformações multiplicativas da razão de sexo o torna útil para comparar períodos com diferentes taxas de participação feminina na força de trabalho.

16 IV Métodos de Medición de La Migración interna (1972).
} 
migrante da amostra é composta por pessoas que efetuaram o deslocamento há pelo menos dez anos. ${ }^{17}$

A ausência do recorte temporal para caracterização do migrante, neste trabalho, justifica-se por dois motivos. Primeiro, a distribuição da população masculina e feminina, de acordo com o tempo de residência, não difere muito (ver apêndice A) e, portanto, os fatores temporais que interferem na diferença salarial entre homens e mulheres (heterogeneidade dos trabalhadores, discriminação e segmentação do mercado de trabalho) estariam igualmente distribuídos na população migrante. Em segundo lugar, ao utilizar o conceito de migrante por UF de nascimento, este trabalho procurou estar de acordo com a literatura econômica que analisa o diferencial de renda entre migrantes e não-migrantes.
Tendo como base o conceito de migrante acumulado, ${ }^{18}$ os dados da PNAD de 2005 mostram que a população migrante brasileira era de aproximadamente $30 \mathrm{mi}$ Ihões de pessoas, sendo que $88,6 \%$ destes localizavam-se em áreas urbanas. Não se verifica discrepância na participação dos migrantes na população segundo o sexo, mas sim quanto à distribuição geográfica. Os dados da Tabela 1 mostram que mais da metade dos migrantes na área urbana encontra-se na Região Sudeste. Já a população migrante que reside na área rural distribui-se de maneira mais homogênea pelo país.

Geralmente os fluxos migratórios ocorrem dos estados mais pobres para os mais ricos. A Tabela 2 mostra que mais da metade dos migrantes que se encontravam na Região Sudeste tem como origem o Nordeste.

TABELA 1

Distribuição da população migrante, por situação de domicílio e sexo Regiões do Brasil - 2005

Em porcentagem

\begin{tabular}{lccccc}
\hline \multirow{2}{*}{ Região } & \multicolumn{2}{c}{ Área rural } & & \multicolumn{2}{c}{ Área urbana } \\
\cline { 2 - 3 } \cline { 5 - 6 } & Mulheres & Homens & & Mulheres & \multicolumn{1}{c}{ Homens } \\
\hline Norte & 24,2 & 26,3 & & 8,9 & 12,0 \\
Nordeste & 20,4 & 20,0 & & 12,7 & 12,5 \\
Sudeste & 24,5 & 22,9 & & 52,2 & 51,2 \\
Sul & 12,4 & 11,1 & 10,9 & 10,8 \\
Centro-Oeste & 18,6 & 19,7 & & 15,3 & 15,5 \\
Participação na população total & $\mathbf{1 0 , 6}$ & $\mathbf{1 1 , 1}$ & & $\mathbf{1 7 , 7}$ & $\mathbf{1 7 , 1}$ \\
\hline
\end{tabular}

Fonte: IBGE. Pesquisa Nacional por Amostra de Domicílios - PNAD 2005. Elaboração própria.

TABELA 2

Distribuição dos migrantes, por região de destino

Regiões do Brasil - 2005

\begin{tabular}{lrcrrrr}
\hline \multirow{2}{*}{ Região de origem } & \multicolumn{7}{c}{ Região de destino } & Em porcentagem \\
\cline { 2 - 7 } & Norte & Nordeste & Sudeste & \multicolumn{1}{c}{ Sul } & Centro-Oeste & Brasil \\
\hline Norte & 24,13 & 4,22 & 1,30 & 1,60 & 5,99 & 4,59 \\
Nordeste & 45,85 & 67,58 & 51,59 & 9,74 & 37,39 & 46,32 \\
Sudeste & 14,03 & 22,84 & 32,77 & 34,71 & 29,89 & 29,54 \\
Sul & 8,19 & 2,38 & 10,81 & 51,13 & 13,45 & 14,24 \\
Centro-Oeste & 7,79 & 2,98 & 3,53 & 2,81 & 13,29 & 5,31 \\
Brasil & $\mathbf{9 , 3 6}$ & $\mathbf{1 1 , 9 4}$ & $\mathbf{5 2 , 6 3}$ & $\mathbf{1 0 , 7 5}$ & $\mathbf{1 5 , 3 3}$ & $\mathbf{1 0 0 , 0 0}$ \\
\hline
\end{tabular}

Fonte: IBGE. Pesquisa Nacional por Amostra de Domicílios - PNAD 2005. Elaboração própria.

\footnotetext{
17 O restante da população migrante divide-se em $9 \%$ que se deslocaram até quatro anos atrás e $10 \%$ entre 5 e 9 anos.

18 Ou população não-natural da Unidade de Federação.
} 
Ainda assim, os movimentos migratórios locais (entre estados da mesma região) são fortes no Nordeste e no Sul do país.

Do ponto de vista econômico, os indivíduos migram devido a uma expectativa de que o padrão de vida (emprego e renda) no local de destino será melhor. Por este motivo, a mobilidade espacial ocupa um lugar de destaque na redistribuição da mão de obra e, consequentemente, na reordenação dos diferenciais de renda nacional. Contudo, apesar da extensão territorial e do volume do fluxo migratório, ${ }^{19}$ não temos na literatura econômica nacional trabalhos que corroborem a ideia de que a migração contribui para a atenuação das disparidades regionais. ${ }^{20}$

O trabalho de Santos Júnior et al. (2005) mostra que os homens migrantes são positivamente selecionados em relação tanto à população de origem quanto à de destino, fazendo com que os autores deduzam que o fluxo de trabalhadores mais produtivos dos estados mais pobres para os mais ricos pode colaborar para a permanência das diferenças inter-regionais de renda no país. ${ }^{21}$

Recentemente, o trabalho de Avelino (2007) contesta os resultados obtidos por Santos Júnior et al. (2005), apontando que, ao requerer mão de obra com qualidade e tipos de habilidades distintas, o mercado de trabalho local das diferentes regiões pode avaliar de maneira diferenciada as características observáveis de migrantes e não-migrantes. Assim, a população migrante desloca-se porque visualiza que seus atributos podem ser mais bem avaliados em outra localidade, e não necessariamente porque é positivamente selecionada. ${ }^{22}$

Os estudos econômicos que comparam os rendimentos entre migrantes e nãomigrantes no Brasil até agora centralizaramse no diferencial de salários da população masculina, mesmo porque a delimitação dos determinantes do deslocamento feminino é muito mais complexa. No entanto, a diferença positiva entre salários de migrantes e não-migrantes também é constada para as mulheres. Dados da PNAD de 2005 para a população em idade ativa mostram que, enquanto os homens migrantes ganham em média $20 \%$ a mais que os não-migrantes, no caso das mulheres esta diferença a favor das migrantes chega a $15 \% .{ }^{23}$

$\mathrm{O}$ fato de a vantagem salarial dos homens migrantes sobre os não-migrantes ser maior do que a observada para as mulheres significa que, também entre a população migrante, o diferencial de renda entre sexo é favorável à população masculina. Percebese ainda que, neste caso, a discrepância é maior do que a verificada na população não-migrante. A Tabela 3 traz os diferenciais brutos do salário/hora de homens e muIheres migrantes de 25 anos ou mais para as áreas urbanas e que realizam trabalhos não-agrícolas.

Os dados mostram que o diferencial de rendimentos entre migrantes e nãomigrantes, apesar de continuar positivo, se reduz bastante quando focalizados apenas trabalhos não-agrícolas em áreas urbanas. Além de o diferencial de salário entre homens e mulheres ser maior na po-

\footnotetext{
19 Dados de 2005 (PNAD) apontam que aproximadamente 6 milhões de pessoas fizeram algum movimento interestadual nos últimos nove anos, o que representa $3,2 \%$ da população total do país.

20 Menezes e Ferreira-Júnior (2003) apresentam resultados pouco robustos para a relação positiva entre migração e velocidade de convergência entre a renda dos estados brasileiros; e Cançado (1999) não constata nenhuma relação entre estas duas variáveis.

21 Utilizando dados da PNAD de 1999, os autores partem de uma equação de rendimentos em que a situação de migração dos indivíduos é mensurada através da inclusão de uma variável dummy. Ao constatarem a significância e o sinal positivo desta variável em duas equações diferentes (a primeira comparando com os não-migrantes no local de destino e a segunda com os não-migrantes que permaneceram no local de origem), os autores apontam que os migrantes são positivamente selecionados.

22 Avelino (2007) mostra que, ao incluir uma dummy para capturar a condição de migração, o trabalho de Santos Júnior et al. (2005) não consegue capturar a diferenciação dos coeficientes das variáveis observáveis, os quais apontam a avaliação distinta que o mercado de trabalho faz dos atributos observáveis dos migrantes e não-migrantes.

23 Refere-se ao conceito de migrante por estado de nascimento e inclui trabalhadores agrícolas e não-agrícolas das áreas rurais e urbanas
} 
pulação migrante (com exceção da Região Sudeste), os dados também mostram que a maior discrepância salarial entre homens e mulheres que residem no mesmo estado em que nasceram acontece no Sudeste, e a menor na Região Norte.

O diferencial de rendimentos entre migrantes e não-migrantes continua sendo sistematicamente maior para a população masculina do que para a feminina. Devido à particularidade da Região Sudeste, onde exclusivamente os não-migrantes ganham mais que do que os migrantes, esta desvantagem da situação da mulher migrante em relação ao homem também de outro estado acaba contribuindo para uma menor discrepância salarial por sexo. Os dados apontam que, ao aplicar o recorte da condição de migração sobre a questão do diferencial de salários por sexo, surgem vários pontos que necessitam ser esclarecidos.

Primeiramente, com relação ao diferencial de salários por sexo na população migrante, questiona-se se as mulheres migrantes possuem características produtivas menos vantajosas do que os homens migrantes, ou ainda se elas teriam suas características observáveis subavaliadas no mercado de trabalho do local de destino em relação aos homens migrantes, vis-à-vis a situação das mulheres não-migrantes perante os homens não-migrantes.

Em segundo lugar, a situação da Região Sudeste, onde se concentra mais da metade da população migrante do país, somada ao fato de ser a única localidade onde o diferencial de rendimento por sexo é menor para a população com origem em outros estados, introduz a questão da inserção ocupacional dos migrantes por sexo. Neste caso, seria o mercado de trabalho segregado não só por sexo, mas também por origem? Ou seja, além de homens e mulheres terem estruturas ocupacionais diferenciadas, também existiria discrepância da distribuição ocupacional de migrantes e não-migrantes, mesmo entre indivíduos do mesmo sexo?

Para responder a estas questões recorremos tanto à decomposição das equações de salários dos grupos migrantes/nãomigrantes e homens/mulheres, por meio da aplicação do método de Oaxaca, quanto ao cômputo do índice de dissimilaridade de Duncan \& Duncan para captar a existência de segregação por sexo e condição de migração.

\section{Métodos empíricos: índice de segregação e decomposição do diferencial de salários}

Entre as causas que podem contribuir para a diferença salarial entre homens e mulheres (independente da condição de migração), estão: a heterogeneidade da produtividade dos indivíduos; a discriminação devido à valorização diferenciada de

TABELA 3

Salário e diferença salarial, por sexo e condição de migração Regióes do Brasil - 2005

Em reais por hora

\begin{tabular}{|c|c|c|c|c|c|c|c|c|}
\hline \multirow{3}{*}{ Região } & \multicolumn{4}{|c|}{ Salário } & \multicolumn{4}{|c|}{ Diferença salarial (1) } \\
\hline & \multicolumn{2}{|c|}{ Homens } & \multicolumn{2}{|c|}{ Mulheres } & \multicolumn{2}{|c|}{ Por sexo } & \multicolumn{2}{|c|}{ Migração } \\
\hline & Não-migrantes & Migrantes & Não-migrantes & Migrantes & Não-migrantes & Migrantes & Homens & Mulheres \\
\hline Norte & 4,79 & 6,61 & 4,40 & 4,74 & 0,39 & 1,87 & $-1,82$ & $-0,34$ \\
\hline Nordeste & 4,60 & 7,45 & 3,86 & 5,33 & 0,74 & 2,12 & $-2,85$ & $-1,47$ \\
\hline Sudeste & 8,12 & 6,47 & 6,18 & 5,12 & 1,94 & 1,35 & 1,65 & 1,06 \\
\hline Sul & 7,33 & 9,10 & 5,48 & 6,28 & 1,84 & 2,82 & $-1,77$ & $-0,80$ \\
\hline Centro-Oeste & 7,05 & 9,14 & 5,46 & 7,24 & 1,59 & 1,90 & $-2,09$ & $-1,78$ \\
\hline Brasil & 6,95 & 7,27 & 5,38 & 5,57 & 1,57 & 1,70 & $-0,33$ & $-0,19$ \\
\hline
\end{tabular}

Fonte: IBGE. Pesquisa Nacional por Amostra de Domicílios - PNAD 2005. Elaboração própria.

(1) Sinal positivo: vantagem do homem ou do não-migrante. Sinal negativo: vantagem da mulher ou do migrante. 
características produtivas idênticas; ou, ainda, a segmentação do mercado de trabalho (quando as ocupações não são igualmente acessíveis entre os indivíduos, apesar de estes serem igualmente qualificados).

Nesta seção é aplicada a técnica de decomposição de Oaxaca para mensurar as duas primeiras parcelas e calcula-se o índice de dissimilaridade de Duncan \& Duncan para captar a existência e o grau da segregação ocupacional, aplicando o recorte de sexo e condição de migração.

$\mathrm{Na}$ análise de segregação ocupacional utilizou-se o agrupamento de ocupações do trabalho principal (semana de referência) presente na PNAD. Como foram excluídos da amostra os trabalhadores agrícolas, somam-se ao todo nove grupos ocupacionais: dirigentes; profissionais das ciências e das artes; técnicos de nível médio; trabalhadores de serviços administrativos; trabalhadores dos serviços; vendedores e prestadores de serviço do comércio; trabaIhadores da produção de bens e serviços e de reparação e manutenção; membros das forças armadas; e ocupações maldefinidas ou não declaradas.

Para que a análise fosse compatível, a equação de rendimentos foi calculada somente com o salário por hora do trabalho principal. Todos os cálculos dizem respeito à área urbana e aos trabalhadores não-agrícolas com idade igual ou superior a 25 anos.

\section{Inserção ocupacional dos migrantes e} segregação no mercado de trabalho de destino

Após introduzir o recorte da condição de migração à questão do diferencial de salários entre homens e mulheres e verificar que, de maneira geral, a discrepância entre os sexos é maior para a população migrante, serão analisados, agora, os fatores que interferem neste quadro.

Supondo-se que os indivíduos migrantes sejam igualmente produtivos aos não-migrantes e que o mercado de trabalho valoriza os dois grupos de maneira idêntica, ainda resta um fator a ser considerado: a parcela referente à segregação ocupacional.
Caso homens e mulheres migrantes não estiverem distribuídos na estrutura ocupacional da mesma maneira que os homens e mulheres não-migrantes, alguma discrepância no diferencial salarial por sexo entre os dois grupos passará a existir.

Para analisar se homens e mulheres migrantes se inserem no mercado de trabalho local de maneira distinta em relação ao grupo correspondente não-migrante, calculou-se o índice de dissimilaridade de Duncan \& Duncan tanto para a segregação por sexo quanto para a de migração. Este indicador é obtido por meio da expressão:

$D=\sum_{j=1}^{J}\left|\left(\frac{Z_{i}}{Z}\right)-\left(\frac{T_{i}}{T}\right)\right| \cdot 100 \cdot \frac{1}{2}$

Sendo:

$\mathrm{J}=$ número total de ocupações;

$Z_{j}=$ número de indivíduos do grupo de análise na ocupação $j$;

$Z$ = número de indivíduos do grupo de análise ocupados na força de trabalho total;

$\mathrm{T}_{j}=$ número de indivíduos do grupo de comparação na ocupação $j$;

$\mathrm{T}=$ número de indivíduos do grupo de comparação ocupados na força de trabalho total.

Assim, o índice D fornece a porcentagem da força de trabalho que deve mudar de ocupação para trazer a correspondência perfeita entre a razão dos dois grupos em cada ocupação e a taxa total de participação do grupo de análise na força de trabalho.

No caso do índice de dissimilaridade por sexo, obteve-se a proporção de indivíduos que devem mudar de ocupação para que a razão de sexo permaneça constante entre as ocupações nas populações migrante e não-migrante. Por sua vez, o índice D por condição de migração aponta a parcela de pessoas que precisam mudar de ocupação para que a razão entre migrantes e não-migrantes seja a mesma ao longo da estrutura ocupacional, tanto de homens quanto de mulheres.

Pela expressão anterior, percebe-se que, quanto maior for o valor de $\mathrm{D}$, mais segregado é o mercado de trabalho. $O$ índice D pode assumir valores entre zero e 100. Ele é igual a zero quando ocorre perfeita 
integração dos dois sexos e/ou das duas condições de migração nas ocupações, ou seja, homens e mulheres e/ou migrantes e não-migrantes têm a mesma estrutura ocupacional.

Por outro lado, D é igual a 100 quando a segregação é total, ou seja, as mulheres empregadas em ocupações inteiramente femininas e os homens nas completamente masculinas. Ou ainda os migrantes empregados em ocupações totalmente destinadas a esta população.

Os resultados presentes na Tabela 4 mostram que, de maneira geral, a segregação por sexo é mais acentuada do que aquela por condição de migração. Para o total do país, mais de $36 \%$ da força de trabalho precisaria ser realocada para que a participação de homens e mulheres nas diversas ocupações seja equiparada à participação total. No caso específico da população migrante, a discrepância da razão por sexo na estrutura ocupacional chega a ser mais elevada do que a verificada para a população não-migrante somente nas Regiões Norte e Sudeste.

Ao se observarem os índices obtidos para a segregação dos migrantes no mercado de trabalho local, chama a atenção a discrepância da Região Sudeste perante o restante do país. Neste caso, a distribuição das mulheres migrantes e não-migrantes dentro da estrutura ocupacional local é bastante acentuada e deve-se, particularmente, à elevada concentração desta população no segmento de serviços, mais especificamente os domésticos. No caso masculino, além do trabalho no setor de serviços, os migrantes também concentram-se nos empregos voltados para a produção.

Quanto às demais regiões, constatase que o baixo grau de segregação dos migrantes é também mais homogêneo entre os sexos nas Regiões Sul e CentroOeste. Já no Norte e no Nordeste, o mercado de trabalho no local de destino faz com que os homens migrantes se insiram de maneira mais segmentada do que as mulheres migrantes vis-à-vis a população não-migrante.

Vale lembrar que o indicador de segregação aponta apenas o quanto a distribuição dos grupos migrantes e não-migrantes entre as ocupações é distinta. Não existe aqui nenhuma indicação de que os migrantes estejam inseridos em ocupações com salários médios mais baixos, ou ainda que a sua origem imponha alguma barreira de acesso a algumas ocupações.

Porém, a possibilidade de inserção ocupacional relaciona-se com o grau de instrução do indivíduo. Ao aplicar o controle da escolaridade, a Tabela 5 mostra que o índice de Duncan diminui ainda mais. Verifica-se também que, na maioria das regiões, a maior segregação ocupacional de acordo com a condição de migração ocorre nas faixas de maior escolaridade. ${ }^{24}$

TABELA 4

Índice de dissimilaridade de Duncan \& Duncan (D) Regióes do Brasil - 2005

\begin{tabular}{lccccc}
\hline \multirow{2}{*}{ Região } & \multicolumn{2}{c}{ Diferença por sexo } & & \multicolumn{2}{c}{ Diferença por migração } \\
\cline { 2 - 3 } \cline { 5 - 6 } Norte & Não-migrantes & Migrantes & & Homens & Mulheres \\
Nordeste & 36,42 & 38,93 & & 7,05 & 4,83 \\
Sudeste & 34,04 & 32,81 & & 11,37 & 6,87 \\
Sul & 36,44 & 39,75 & & 14,55 & 20,88 \\
Centro-Oeste & 39,48 & 35,18 & 6,51 & 6,76 \\
Brasil & 39,06 & 38,42 & & 7,04 & 7,19 \\
\hline
\end{tabular}

Fonte: IBGE. Pesquisa Nacional por Amostra de Domicílios - PNAD 2005. Elaboração própria.

24 A exceção são os casos da população feminina no Nordeste e a masculina no Sudeste e Centro-Oeste. 
TABELA 5

Índice de dissimilaridade de Duncan \& Duncan (D) por condição de migração - controlado por escolaridade Regiões do Brasil - 2005

Em porcentagem

\begin{tabular}{|c|c|c|c|c|c|c|c|c|c|c|}
\hline \multirow{2}{*}{ Anos de estudo } & \multicolumn{2}{|c|}{ Norte } & \multicolumn{2}{|c|}{ Nordeste } & \multicolumn{2}{|c|}{ Sudeste } & \multicolumn{2}{|c|}{ Sul } & \multicolumn{2}{|c|}{ Centro-Oeste } \\
\hline & Homens & Mulheres & Homens & Mulheres & Homens & Mulheres & Homens & Mulheres & Homens & Mulheres \\
\hline 0 anos & 2,75 & 4,90 & 7,92 & 10,61 & 7,30 & 4,82 & 9,71 & 8,75 & 11,87 & 5,64 \\
\hline 1 a 4 anos & 7,34 & 5,92 & 6,62 & 6,78 & 2,89 & 2,94 & 5,92 & 3,30 & 9,92 & 4,22 \\
\hline 5 a 8 anos & 6,25 & 5,23 & 10,96 & 6,39 & 3,86 & 3,18 & 5,23 & 9,14 & 5,51 & 8,54 \\
\hline 9 a 11 anos & 9,21 & 5,37 & 9,10 & 7,43 & 8,05 & 14,76 & 11,60 & 10,69 & 11,31 & 11,08 \\
\hline 12 anos ou mais & 11,46 & 6,48 & 11,66 & 6,87 & 6,18 & 9,63 & 11,47 & 11,98 & 8,51 & 8,47 \\
\hline Total & 7,05 & 4,83 & 11,37 & 6,87 & 14,55 & 20,88 & 6,51 & 6,76 & 7,04 & 7,19 \\
\hline
\end{tabular}

Fonte: IBGE. Pesquisa Nacional por Amostra de Domicílios - PNAD 2005. Elaboração própria.

De maneira geral, os baixos valores obtidos para o índice $D$ relativizam a relevância de se considerar a diferença da inserção ocupacional de homens e mulheres migrantes em relação à população não-migrante no mercado de trabalho local como uma das possíveis explicações para a maior divergência salarial por sexo verificada para o primeiro grupo. Ainda assim, a situação do Sudeste merece destaque devido à grande diferenciação do indicador.

\section{Decomposição do diferencial de salários}

Após a estimação das equações de rendimentos do trabalho, por meio do procedimento de Heckman, ${ }^{25}$ inicia-se a análise do diferencial de salários. A diferença salarial entre homens/mulheres, migrantes/não-migrantes é então decomposta entre: atributos pessoais (produtivos ou não); características do posto de trabalho; e características não observadas diretamente.

A técnica utilizada para realizar essa decomposição é conhecida como "decomposição de Oaxaca", apresentada a seguir de maneira sucinta. ${ }^{26}$ Reformulando a equação de rendimentos estimada, obtém-se:

$\ln w_{i m}=\alpha_{m}+\sum \theta_{i m} W_{i m}+\varepsilon_{i} \quad(m=1,2)$ onde:

$\sum \theta_{i m} W_{i m}=\sum \beta_{i m} X_{i m}+\sum d_{i m} Z_{i m}$ agrega as variáveis observáveis referentes aos atributos pessoais e as características do posto do trabalho.

Neste trabalho, o indicador $m$ pode ser tanto o sexo, quando se realiza a decomposição salarial entre homens $(m=1)$ e mulheres $(m=2)$, quanto a condição de migração, no caso da análise do diferencial de salário entre não-migrantes $(m=1)$ e migrantes $(m=2)$.

O procedimento da decomposição de Oaxaca parte sempre de pares de equações para obter o diferencial de rendimentos. Nesse caso, haverá duas diferenças a serem calculadas (por sexo e por condição de migração), mas que são calculadas da mesma maneira:

Diferencial de salário:

$\ln W_{i 1}-\ln W_{i 2}=\left(\alpha_{1}-\alpha_{2}\right)+\sum W_{i 2}\left(\theta_{i 1}-\theta_{i 2}\right)+\sum \theta_{i 1}\left(W_{i 1}-W_{i 2}\right)$

O diferencial possui três componentes. O primeiro $\left(\alpha_{1}-\alpha_{t}\right)$, que constitui a diferença dos interceptos, mede os diferenciais de rendimentos devido às características específicas dos trabalhadores segundo

\footnotetext{
25 O procedimento de Heckman trata do problema de seletividade amostral; quando a pessoa sem remuneração não está inserida no mercado de trabalho por opção, pois seu salário reserva é maior do que o salário em vigor no mercado. Nesse caso, para se obterem estimativas consistentes, é preciso corrigir o viés da seleção. A equação estimada do salário/hora é dada por: $\ln w_{i}=\alpha+\beta X_{i}+\delta Z_{i}+\varepsilon_{i}$, onde: $w$ é a renda do trabalho principal por hora dos indivíduos; $X_{i}$ é o vetor das variáveis explicativas das características individuais; e $Z_{i}$ é o vetor de variáveis relacionadas ao posto de trabalho.

${ }^{26}$ A exposição completa da técnica pode ser obtida em Oaxaca (1973).
} 
sexo/condição de migração, independente das características do trabalho e de seus atributos produtivos.

O segundo termo, $\sum W_{i t}\left(\theta_{i 1}-\theta_{i t}\right)$, é a parte da diferença de salários que se deve à valoração diferenciada do sexo/condição de migração. Se a diferença dos coeficientes for positiva, evidencia que existe maior valoração dos homens ou da situação de nãodeslocamento geográfico (não-migrantes) em detrimento da mulher ou da experiência migratória. Esse termo testa se as diferenças dos coeficientes estimados das variáveis explicativas também se devem ao sexo e à migração. Somando-se este segundo termo ao primeiro, obtém-se uma medida para a remuneração não condicionada às características do trabalho e dos atributos pessoais, conhecida na literatura como "discriminação".

Finalmente, o terceiro termo, $\sum \theta_{i 1}\left(W_{i 1}-W_{i t}\right)$, representa os diferenciais de rendimentos do trabalho relativos a dotações distintas dos atributos pessoais de homens e mulheres/não-migrantes e migrantes. Assim, quem é mais dotado em algum atributo valorizado pelo mercado, como, por exemplo, educação e experiência, tem um salário mais elevado. Essa é a porção do rendimento do trabalho que é considerada justificável.

A maioria dos trabalhos econômicos que tratam da diferença de rendimentos entre migrantes e não-migrantes mensura essa discrepância exclusivamente pela inclusão de uma variável dummy na equação estimada que separa a amostra entre esses dois grupos. No entanto, esse procedimento capta apenas a diferença referente ao intercepto, esquecendo-se de que o impacto das variáveis explicativas também pode ser distinto de acordo com a condição de migração do indivíduo.

Para avaliar melhor o quebra-cabeça da relação migração-diferença salarial por gênero-discriminação, estimou-se a equação de rendimento para homens e mulheres segundo a condição de migração, para depois aplicar a decomposição de Oaxaca. Devido à grande particularidade da Região Sudeste, esta foi estimada separadamente do restante do país, somando-se ao todo oito equações.

A Tabela 6 traz os resultados da diferença salarial entre homens e mulheres segundo a condição de migração. Apesar de a vantagem ser masculina independentemente da condição de migração e da área territorial, a decomposição permite a realização de uma análise mais apurada, pois desmembra a diferença salarial em componentes justificáveis e de discriminação.

Os dados mostram que, na maioria dos casos, a dimensão do diferencial ajustado mantém a vantagem masculina devido ao

TABELA 6

Decomposição de Oaxaca - Diferencial de salários por sexo Brasil - 2005

\begin{tabular}{lccccc}
\hline \multirow{2}{*}{ Diferença imputável a: } & \multicolumn{2}{c}{ Brasil sem SE } & & \multicolumn{2}{c}{ Sudeste } \\
\cline { 2 - 3 } \cline { 5 - 6 } & Não-migrantes & Migrantes & & Não-migrantes & Migrantes \\
\hline Atributos (A) & $-0,1$ & 19,8 & & 4,7 & 10,6 \\
$\quad$ Dotação (D) & $-2,8$ & 2,0 & 1,8 & 10,9 \\
$\quad$ Coeficientes (C) & 2,7 & 17,8 & 2,9 & $-0,3$ \\
Deslocamento da constante (U) & 21,3 & 10,7 & 21,6 & 16,3 \\
Diferencial bruto (B = D+C+U) & 21,2 & 30,5 & 26,3 & 26,9 \\
Diferencial ajustado (E = C+U) & $\mathbf{2 4 , 0}$ & $\mathbf{2 8 , 5}$ & & $\mathbf{2 4 , 5}$ & $\mathbf{1 6 , 0}$ \\
Dotação - \% total (D/B) & $-13,21$ & 6,56 & & 6,84 & 40,52 \\
Discriminação - \% total (E/B) & 113,21 & 93,44 & & 93,16 & 59,48 \\
Vantagem & Homem & Homem & Homem & Homem
\end{tabular}

Fonte: IBGE. Pesquisa Nacional por Amostra de Domicílios - PNAD 2005. Elaboração própria.

Nota: Valores positivos do diferencial ajustado indicam a vantagem da categoria base (homens), e valores negativos, o contrário. 
deslocamento na constante. ${ }^{27}$ Nesse caso, a vantagem salarial dos homens em relação às mulheres deve-se a fatores específicos não relacionados às características do trabalho e dos atributos produtivos dos trabalhadores.

Somente no caso da diferença salarial por sexo para a população migrante residente na Região Sudeste foi encontrado um elevado peso para o diferencial dos atributos produtivos entre homens e mulheres, com desvantagem para este último grupo. Por outro lado, mesmo apresentando uma magnitude pequena, o sinal negativo obtido neste mesmo diferencial para o componente referente à diferença dos coeficientes indica que o mercado de trabalho na região dá maior valor às características específicas das mulheres migrantes do que às dos homens também migrantes.

Em contrapartida, no restante no país, o diferencial de salários entre homens e mulheres migrantes se mantém devido ao fato de o mercado de trabalho no local de destino valorizar muito mais os atributos dos homens migrantes do que os das mulheres.

Um ponto importante diz respeito à inclusão da ocupação na equação de ren- dimentos estimados. Através das dummies para a ocupação, as diferenças obtidas aqui estão sendo controladas pela possível diferença intraocupacional, ou seja, a discrepância verificada nos salários entre homens e mulheres dentro de uma mesma ocupação. Mas a parcela da diferença salarial por sexo que se deve à distribuição diferenciada dos grupos dentro da estrutura ocupacional não é captada pelo segundo e nem pelo terceiro termo da decomposição de Oaxaca, estando, portanto, incluída a discrepância das constantes. ${ }^{28}$ Por esse motivo, calculou-se o índice de dissimilaridade apresentado anteriormente.

O elevado índice de segregação total ${ }^{29}$ entre migrantes e não-migrantes, no caso do Sudeste, somado às particularidades desta região, indica que as diferenças observadas entre os salários de homens e mulheres migrantes devem ser abordadas respeitando-se as especificidades do mercado de trabalho no qual estes procuram inserir-se. Por esse motivo, também foi calculada a decomposição de Oaxaca para o diferencial de salário por condição de migração.

Percebe-se que a vantagem salarial da população migrante é bem menor no

TABELA 7

Decomposição de Oaxaca - Diferencial de salários por migração Brasil - 2005

\begin{tabular}{|c|c|c|c|c|}
\hline \multirow{2}{*}{ Diferença imputável a: } & \multicolumn{2}{|c|}{ Brasil sem SE } & \multicolumn{2}{|c|}{ Sudeste } \\
\hline & Homens & Mulheres & Homens & Mulheres \\
\hline Atributos (A) & $-43,2$ & $-23,3$ & 47,7 & 53,8 \\
\hline Dotação (D) & $-14,7$ & $-9,2$ & 12,4 & 13,5 \\
\hline Coeficientes (C) & $-28,5$ & $-14,1$ & 35,3 & 40,3 \\
\hline Deslocamento da constante (U) & 15,0 & 4,3 & $-36,9$ & $-42,2$ \\
\hline Diferencial bruto $(B=D+C+U)$ & $-28,2$ & $-19,0$ & 10,8 & 11,6 \\
\hline Diferencial ajustado $(E=C+U)$ & $-13,5$ & $-9,8$ & $-1,6$ & $-1,9$ \\
\hline Dotação - \% total (D/B) & 52,13 & 48,42 & 114,81 & 116,38 \\
\hline Discriminação - \% total (E/B) & 47,87 & 51,58 & $-14,81$ & $-16,38$ \\
\hline Vantagem & Migrante & Migrante & Migrante & Migrante \\
\hline
\end{tabular}

Fonte: IBGE. Pesquisa Nacional por Amostra de Domicílios - PNAD 2005. Elaboração própria. Nota: Valores positivos do diferencial ajustado indicam a vantagem da categoria base (não-migrantes), e valores negativos, o contrário.

\footnotetext{
27 Exceção para a amostra nacional - sem contabilizar o Sudeste - da população migrante.

28 Vale apontar que Brown et al. (1980) criticam a inclusão da variável referente à ocupação nas equações de rendimentos, pois, para esses autores, a ocupação é uma variável endógena ao processo de determinação salarial.

29 Sem aplicação do controle de escolaridade (Tabela 4).
} 
Sudeste do que no resto do país, tanto para homens quanto para mulheres. Mais ainda, este ganho estreito baseia-se nas características específicas dos migrantes (homens e mulheres) e não em sua dotação produtiva, ou ainda na valoração superior que o mercado de trabalho local faz de seus atributos. Dessa maneira, verifica-se que a menor vantagem salarial do homem migrante na Região Sudeste contribui para o fato de o diferencial de salário em relação às mulheres ser menor para este grupo da população em comparação aos não-migrantes.

Por outro lado, no restante do país, os migrantes não só apresentam atributos produtivos superiores aos da população não-migrante, como também o mercado de trabalho local precifica melhor seus atributos em relação à população local. A valoração superior dos atributos migrantes do mercado local é tão maior que a da população não-migrante que, neste caso, supera com grande margem a vantagem das características específicas da população não-migrante. Nessa situação, a maior discrepância dos salários entre homens e mulheres migrantes vis-à-vis os não-migrantes deve-se praticamente à melhor avaliação do mercado dos atributos dos homens migrantes.

\section{Considerações finais}

Por meio da desagregação do diferencial de salários segundo a condição de migração da população, constatou-se que, de maneira geral, as mulheres migrantes encontram-se em situação ainda mais desvantajosa do que os homens quando comparadas às mulheres não-migrantes. No entanto, a região onde se concentra a maior parte dos migrantes do país é justamente a exceção a esta regra.

O trabalho traz várias questões e nem todas ainda estão devidamente respondidas, mas, perante os resultados obtidos, algumas linhas gerais podem ser vislumbradas. Primeiramente, percebe-se que o mercado de trabalho nacional não é segregado em termos de condição de migração. Ainda assim, é importante ressaltar que o indicador mais elevado de Duncan para o Sudeste, particularmente no caso das mu-
Iheres, aponta que nesta região existe algum viés da alocação dos migrantes dentro da estrutura ocupacional.

Nesse caso, existiria não só uma discrepância na participação por sexo na estrutura ocupacional, mas também uma segregação entre migrantes e não-migrantes, tanto no mercado feminino quanto no masculino. No entanto, ao aplicar o controle por anos de estudo, a segregação observada entre migrantes e não-migrantes no Sudeste se dilui. Este resultado evidencia que tanto mulheres quanto homens deslocam-se para essa região (ou mesmo dentro dela) nem tanto para auferir ganhos da valoração diferenciada dos atributos presentes no mercado de trabalho local, mas sim para se inserir em ocupações específicas, dado o grau de instrução que possuem.

Em segundo lugar, a pergunta básica referente ao diferencial de salários por sexo na população migrante era se a desvantagem das mulheres migrantes devia-se a características produtivas ou se elas teriam suas características observáveis subavaliadas no mercado de trabalho do local de destino em relação aos homens migrantes, vis-à-vis a situação das mulheres não-migrantes perante os homens não-migrantes.

Nesse caso têm-se dois quadros: um para a Região Sudeste, onde a diferença salarial por sexo é menor entre a população migrante do que a não-migrante, e outro para o resto do Brasil, onde ocorre o contrário.

Os resultados obtidos (Tabela 6) mostram que, no caso do Sudeste, a menor diferença salarial por sexo na população migrante deve-se ao fato de as características específicas de homens e mulheres migrantes serem menos heterogêneas do que aquelas observadas na população nãomigrante. Ou seja: o mercado de trabalho no Sudeste diferencia menos homens e mulheres migrantes, independentemente dos atributos produtivos, do que o faz entre homens e mulheres não-migrantes.

No que se refere à diferença de atributos produtivos, os homens migrantes sobressaem em relação às mulheres, contudo, o sinal negativo da diferença do coeficiente estimado indica que, no Sudeste, o mercado sobrevaloriza as características observáveis 
das mulheres migrantes em relação aos homens. ${ }^{30}$

No resto do Brasil, a maior diferença salarial por sexo ocorre na população migrante. Nesse caso, o principal motivo deve-se à valoração muito acima que o mercado de trabalho local faz dos atributos dos homens migrantes em relação aos das mulheres migrantes. Já entre a população

\section{Referências}

ALVES, E. L. G.; AMORIN, B. M. F.; CUNHA, G. H. de M. Emprego e ocupação: algumas evidências da evolução do mercado de trabalho por gênero na Grande São Paulo - 1988/1995. Brasília: Ipea, 1997 (Texto para discussão, n. 497).

ARAÚJO, V. F.; RIBEIRO, E. P. Diferenciais de salários por gênero no Brasil: uma análise regional. Revista Econômica do Nordeste, Fortaleza, v. 33, n.2, abr.-jun. 2002.

AVELINO, R. R. G. Self-selection and impact of migration on earnings, 2007. Mimeografado.

BARROS, R. P.; RAMOS, L.; SANTOS, E. Gender differences in brazilian labor markets: investment in women's human capital. Chicago: University of Chicago, 1995.

BARROS, R. P.; CORSEUIL, C. H.; SANTOS, D.D. A natureza da inserção feminina e dos diferenciais por gênero no mercado de trabalho da Região Metropolitana de São Paulo. Mercado de Trabalho - conjuntura e análise, Ipea, n. 13, junho 2000.

BLINDER, A. S. Wage discrimination: reduced form and structural variables. Journal of Human Resources, v. 8, 1973.

BROWN, R. S.; MOON, M.; ZOLOTH, B. S. Incorporating occupational attachment in studies of male-female earnings differentials. Journal of Human Resources, v. 15, 1980.

BRUSCHINI, C. Gênero e trabalho no Brasil: novas conquistas ou persistência da discriminação? (Brasil: 1985/1995). In: não-migrante, as mulheres têm atributos produtivos melhores do que os homens, apesar de o mercado valorizar mais os atributos masculinos do que os femininos. $\mathrm{Na}$ população migrante, os homens encontramse em melhor situação do que as mulheres em todas as parcelas da decomposição: atributos, valoração do mercado e características específicas.

ROCHA, M. I. B. (Org.). Trabalho e gênero - mudanças, permanências e desafios. Abep, Nepo, Cedeplar. São Paulo: Editora 34, 2000.

CANÇADO, R. P. Migrações e convergência no Brasil: 1960-1991. Revista Brasileira de Economia, Rio de Janeiro, abr.-jun. 1999.

CHAVES, M. de F. G. Migração feminina: familiar ou autônoma? Observações sobre as mulheres que migram solteiras e separadas. In: XIV ENCONTRO NACIONAL DE ESTUDOS POPULACIONAIS, XIV. Anais... Caxambu/MG, Abep, 2004.

DUNCAN, O. D.; DUNCAN, B. A methodological analysis of segregation indices. American Sociological Review, v. 20, 1955.

HECKMAN, J. J. Sample selection as a specification error. Econometrica, v. 47, n. 1, 1979.

KON, A. Segmentação ocupacional brasileira segundo gênero. In: ENCONTRO NACIONAL DE ESTUDOS DO TRABALHO. Anais... São Paulo: ABRT, 1999.

LEME, M. C.; WAJNMAN, S. Efeitos de período, coorte e ciclo de vida na participação feminina no mercado de trabalho brasileiro, 1999. Mimeografado.

MACHADO, A. F.; OLIVEIRA, A. M. H. C.; WAJNMAN, S. Sexo frágil? Evidências sobre a inserção da mulher no mercado de trabalho brasileiro. São Paulo: Organização Gelre, 2005 (Série estudos do trabalho, coletânea Gelre).

30 No resto do país ocorre o contrário 
MENEZES, T.; FERREIRA JUNIOR, D. Migração e convergência de renda. In: FÓRUM DO BANCO DO NORDESTE DE DESENVOLVIMENTO E VIII ENCONTRO REGIONAL DE ECONOMIA. Anais... Fortaleza, 2003.

MATOS, R. S.; MACHADO, A. F. Diferencial de rendimentos por cor e sexo no Brasil (1987-2001). Econômica, Rio de Janeiro, v. 8, n.1, junho 2006.

OLIVEIRA, A. M. H. C. Indicadores da segregação ocupacional por sexo no Brasil. In: ENCONTRO NACIONAL DE ESTUDOS POPULACIONAIS, XI. Anais... Abep, 1998.

OLIVEIRA, K. F.; JANNUZZI, P. M. Motivos para migração no Brasil: padrões etários, por sexo e origem/destino. In: ENCONTRO NACIONALDE ESTUDOS POPULACIONAIS, XIV. Anais... Abep, 2004.

OMETTO, A. M. H.; HOFFMANN, R.; ALVES, M. C. Participação da mulher no mercado de trabalho: discriminação em Pernambuco e São Paulo. Revista Brasileira de Economia, Rio de Janeiro, jul.-set. 1999.

A segregação por gênero no

mercado de trabalho nos Estados de São
Paulo e Pernambuco. Economia Aplicada, v. 1, n. 3, 1997.

OAXACA, R. Male-female wage differentials in urban labor markets. International Economic Review, 14 (4): 693-709, 1973.

SANTOS JUNIOR, E. R.; MENEZES FILHO, N. A.; FERREIRA, P. C. Migração, seleção e diferenças regionais de renda no Brasil. Pesquisa e Planejamento Econômico, Rio de Janeiro, v. 35, n. 3, p. 299-332, 2005.

SCORZAFAVE, L. G.; MENEZES FILHO, N. A. Participação feminina no mercado de trabalho brasileiro: evolução e determinantes. Pesquisa e Planejamento Econômico, Rio de Janeiro, v. 31, n. 3, p. 441-478, 2001.

SOARES, C. Os impactos das novas tecnologias no emprego, gênero e qualificação nas atividades de escritório. Niterói: UFF, 2001. Mimeografado.

SOARES, C.; OLIVEIRA, S. Gênero, estrutura ocupacional e diferenciais de rendimento. Econômica, Rio de Janeiro, v. 6, n.1, junho 2004.

\section{Apêndice A}

Distribuição da população migrante, por sexo, segundo o tempo de residência Brasil - 2005

\begin{tabular}{lcc} 
& & Em porcentagem \\
\hline Tempo de residência na UF & Homens & Mulheres \\
\hline Até 4 anos & 9,7 & 8,4 \\
5 a 9 anos & 10,6 & 10,6 \\
10 anos ou mais & 79,7 & 81,0 \\
Total & $\mathbf{1 0 0 , 0}$ & $\mathbf{1 0 0 , 0}$ \\
\hline
\end{tabular}

Fonte: IBGE. Pesquisa Nacional por Amostra de Domicílios - PNAD 2005. Elaboração própria.

\section{Apêndice B}

\section{Descrição das variáveis presentes na estimação da equação de salários}

Variáveis dependentes:

- equação de seleção (Heckman): variável dummy que indica se o indivíduo trabalha ou não. Assume valor 1 para aqueles que trabalham e zero em caso contrário;

- equação de rendimentos: logaritmo da renda do trabalho principal na semana de referência por hora dos indivíduos. 
Variáveis das características individuais ou familiares:

- escolaridade: variável contínua que indica o grau de instrução da pessoa através do número de anos de estudo pertencente ao intervalo [0,17];

- experiência no mercado de trabalho: a proxy utilizada neste trabalho refere-se à idade da pessoa descontada dos anos pré-escolares;

- experiência ao quadrado: deve-se à aplicação da forma quadrática "minceriana" que sugere que a contribuição do capital humano adquirido no próprio mercado de trabalho cresce a taxas decrescentes;

- escolaridade X experiência: variável responsável pela mensuração da capacitação da pessoa (tanto para encontrar um emprego quanto para auferir rendimentos mais elevados);

- cor: variável dummy que indica a cor da pele da pessoa. Assume valor nulo para as pessoas denominadas brancas e amarelas e valor 1 para as pretas, pardas ou indígenas;

- responsável: variável dummy que indica a posição familiar da pessoa. Assume valor 1 para os que são responsáveis pela família e zero em caso contrário;

- casado: variável dummy que indica a situação conjugal. Assume valor 1 para os que possuem cônjuge e zero em caso contrário;

- filhos: variável dummy que indica se o indivíduo possui ou não filhos. Assume valor 1 para os que possuem filhos e zero em caso contrário;

- rendimento do não-trabalho: total de renda advinda de fontes que não o trabalho.

Variáveis das características do posto de trabalho:

- ocupação: foram utilizadas dummies para nove grupos ocupacionais:

- ocupação 1 = dirigentes;

- ocupação 2 = profissionais das ciências e das artes;

- ocupação 3 = técnicos de nível médio;

- ocupação 4 = trabalhadores de serviços administrativos;

- ocupação 5 = trabalhadores dos serviços;

- ocupação 6 = vendedores e prestadores de serviço do comércio;

- ocupação 7 = trabalhadores da produção de bens e serviços e de reparação e manutenção;

- ocupação 8 = membros das forças armadas;

- ocupação 9 = ocupações maldefinidas ou não declaradas.

- posição na ocupação: foram utilizadas dummies para empregado com carteira, funcionário público, empregado sem carteira, trabalhador doméstico com carteira, trabalhador doméstico sem carteira, conta própria e empregador. Devido ao problema de colinearidade, a dummy referente à posição empregado com carteira foi omitida da estimação. Em cada um destes casos, a variável dummy assumiu valor 1 quando a pessoa encontra-se na posição especificada e zero em caso contrário;

- RMSP: dummy que indica o local de residência do indivíduo, assume valor 1 para a região metropolitana e zero para as demais localidades;

- área metropolitana: dummy que indica o local de residência do indivíduo, assume valor 1 para a região metropolitana e zero para as demais localidades;

- região/estados: dummy que indica o local de residência do indivíduo, assume valor 1 para a regiões Norte, Nordeste, Sudeste, Sul e Centro-Oeste. Na regressão da Região Sudeste foram incluídas variáveis dummy para os Estados do Rio de Janeiro, Espírito Santo e Minas Gerais. 


\section{Apêndice C}

Resultados da equação de salários, por sexo e condição de migração Brasil urbano - não-agrícola

\begin{tabular}{|c|c|c|c|c|}
\hline \multirow{2}{*}{ Variáveis } & \multicolumn{2}{|c|}{ Homens } & \multicolumn{2}{|c|}{ Mulheres } \\
\hline & Não-migrantes & Migrantes & Não-migrantes & Migrantes \\
\hline \multicolumn{5}{|l|}{ Seleção - Probit } \\
\hline Anos de estudo & $0,04426^{\star *}$ & $0,03740^{\star *}$ & $0,06536^{\star *}$ & $0,06536 * *$ \\
\hline Experiência & $0,05707^{\star *}$ & $0,03524 * *$ & $0,03029 * *$ & $0,03029 * *$ \\
\hline Exp. ao quadrado & $-0,00072^{\star *}$ & $-0,00053^{\star *}$ & $-0,00046^{* *}$ & $-0,00046^{\star \star}$ \\
\hline Escolaridade X exp. & $-0,00046^{* *}$ & $-0,00026^{\star *}$ & $-0,00062^{\star *}$ & $-0,00062^{\star *}$ \\
\hline Cor & $-0,04535^{\star *}$ & $-0,01259 * *$ & $0,09499 * *$ & $0,09499 * *$ \\
\hline Responsável fam. & $0,39805^{\star \star}$ & $0,51158^{* *}$ & $0,75159 * \star$ & $0,75159 * \star$ \\
\hline Casado & $-0,20553^{* *}$ & $-0,14639 * \star$ & $-0,19373^{\star *}$ & $-0,19373^{\star *}$ \\
\hline Filhos & $0,06293^{\star *}$ & $0,05172^{\star *}$ & $0,01752^{\star *}$ & $0,01752^{\star \star}$ \\
\hline Região Norte & $0,10068 * *$ & $0,01705^{* *}$ & $-0,09175^{\star *}$ & $-0,09175^{\star \star}$ \\
\hline Região Sul & $0,26728^{* *}$ & $0,26227^{* *}$ & $0,18826^{\star *}$ & $0,18826^{\star *}$ \\
\hline Região Centro-Oeste & $0,18280 * *$ & $0,13970 * *$ & $0,15503^{* *}$ & $0,15503^{* \star}$ \\
\hline Área metropolitana & $0,07648^{\star *}$ & $-0,08987^{\star *}$ & $0,34995^{\star \star}$ & $0,34995^{\star \star}$ \\
\hline Rendimento do não-trabalho & $-0,00007^{\star *}$ & $-0,00004^{\star *}$ & $-0,00018^{\star *}$ & $-0,00018^{\star *}$ \\
\hline Constante & $0,92162^{\star *}$ & $1,35927^{\star \star *}$ & $0,69891 * *$ & $0,69891^{\star *}$ \\
\hline \multicolumn{5}{|l|}{ Salário/hora } \\
\hline Anos de estudo & $0,03873^{\star *}$ & $0,05398^{* *}$ & $0,05092^{\star *}$ & $0,06152^{\star *}$ \\
\hline Experiência & $0,02970 * *$ & $0,03917^{* *}$ & $0,02437^{* *}$ & $0,02303^{\star *}$ \\
\hline Exp. ao quadrado & $-0,00033^{* *}$ & $-0,00045^{* *}$ & $-0,00024 * *$ & $-0,00021^{\star *}$ \\
\hline Escolaridade X exp. & $0,00087^{\star *}$ & $0,00073^{* *}$ & $0,00036^{\star *}$ & $0,00028^{* *}$ \\
\hline Cor & $-0,11191^{* *}$ & $-0,11127^{\star *}$ & $-0,09533^{\star *}$ & $-0,14017^{\star \star}$ \\
\hline Ocupação 2 & $0,17365^{\star *}$ & $0,18180^{* *}$ & $0,00962^{* *}$ & $0,07967^{* *}$ \\
\hline Ocupação 3 & $-0,19946^{\star \star}$ & $-0,16429 * *$ & $-0,23755^{\star \star}$ & $-0,25637^{\star \star}$ \\
\hline Ocupação 4 & $-0,49585^{\star \star}$ & $-0,50036^{\star *}$ & $-0,43988^{\star *}$ & $-0,45359 * *$ \\
\hline Ocupação 5 & $-0,74548^{\star *}$ & $-0,77838^{\star *}$ & $-0,59601 * *$ & $-0,63103^{\star *}$ \\
\hline Ocupação 6 & $-0,59998^{\star *}$ & $-0,55592^{\star *}$ & $-0,60885^{\star *}$ & $-0,55407$ \\
\hline Ocupação 8 & $-0,55883^{\star *}$ & $-0,57140 * *$ & $-0,82070^{* *}$ & $-0,70041^{* *}$ \\
\hline Ocupação 9 & $-0,17796$ ** & $-0,11738^{\star *}$ & $0,14427^{\star \star}$ & $0,24801^{* *}$ \\
\hline Funcionário público & $0,22565^{\star *}$ & $0,30273^{\star *}$ & $0,18130 * *$ & $0,30792^{\star *}$ \\
\hline Empregado sem carteira & $-0,23668^{\star *}$ & $-0,20295^{\star \star}$ & $-0,15679 * \star$ & $-0,08564^{* *}$ \\
\hline Trab. doméstico com carteira & $-0,21488^{\star *}$ & $-0,30484^{\star *}$ & $-0,15891 * *$ & $-0,08430 * *$ \\
\hline Trab. doméstico sem carteira & $-0,29001^{\star *}$ & $-0,24551^{* *}$ & $-0,31536^{\star *}$ & $-0,16040^{\star *}$ \\
\hline Conta própria & $-0,13745^{\star \star}$ & $-0,07743^{\star \star}$ & $-0,09316^{\star \star}$ & $0,00233^{* *}$ \\
\hline Empregador & $0,20977^{\star *}$ & $0,24825^{\star \star}$ & $0,23336^{\star \star}$ & $0,28605^{\star *}$ \\
\hline Região Norte & $0,16902^{\star \star}$ & $0,21303^{* *}$ & $0,23908^{\star *}$ & $0,19450^{\star *}$ \\
\hline Região Sul & $0,31213^{\star *}$ & $0,25743^{\star *}$ & $0,34232^{\star \star}$ & $0,31692^{* *}$ \\
\hline Região Centro-Oeste & $0,32474 * \star$ & $0,27319 * \star$ & $0,34347 * *$ & $0,31610^{* *}$ \\
\hline Área metropolitana & $0,05852^{\star *}$ & $0,12231 * *$ & $0,13461 * *$ & $0,23646^{\star *}$ \\
\hline constante & $0,54645^{\star *}$ & $0,39683^{* *}$ & $0,33346^{\star *}$ & $0,29006^{* *}$ \\
\hline № observações & 10.400 .000 & 2.986 .947 & 8.723 .170 & 2.368 .916 \\
\hline № obs. censuradas & 91.991 & 24.939 & 349.189 & 115.805 \\
\hline Wald chi2 (22) & 8.570 .000 & 3.130 .000 & 6.630 .000 & 2.230 .000 \\
\hline Prob > chi2 & 0,0000 & 0,0000 & 0,0000 & 0,0000 \\
\hline
\end{tabular}

Nota: A Região Sudeste foi excluída desta amostra ** Significância a $5 \%$. 
Região Sudeste urbana - não-agrícola

\begin{tabular}{|c|c|c|c|c|}
\hline \multirow{2}{*}{ Variáveis } & \multicolumn{2}{|c|}{ Homens } & \multicolumn{2}{|c|}{ Mulheres } \\
\hline & Não-migrantes & Migrantes & Não-migrantes & Migrantes \\
\hline \multicolumn{5}{|l|}{ Seleção - Probit } \\
\hline Anos de estudo & $0,03737^{\star *}$ & $0,04310 * *$ & $0,08341^{* *}$ & $0,06909 * *$ \\
\hline Experiência & $0,05447^{* *}$ & $0,04786^{\star *}$ & $0,04047^{* *}$ & $0,02776^{\star *}$ \\
\hline Exp. ao quadrado & $-0,00082^{* *}$ & $-0,00067^{\star *}$ & $-0,00055^{\star \star}$ & $-0,00043^{* *}$ \\
\hline Escolaridade X exp. & $-0,00042^{* *}$ & $-0,00064 * *$ & $-0,00143^{* *}$ & $-0,00134^{\star *}$ \\
\hline Cor & $0,10929 * *$ & $-0,02819^{\star *}$ & $0,12096 * *$ & $0,17777^{* *}$ \\
\hline Responsável fam. & $0,45086^{* *}$ & 0,00649 & $0,15211^{* *}$ & $0,44182^{* *}$ \\
\hline Casado & $0,00957^{\star *}$ & $-0,01130$ & $-0,28938^{\star *}$ & $-0,13592^{\star *}$ \\
\hline Filhos & $0,09695^{\star *}$ & $-0,08940 * *$ & $-0,07173^{* \star}$ & $0,07148^{* *}$ \\
\hline Rio de Janeiro & $0,08625^{\star *}$ & $-0,01114^{*}$ & $0,25850 * *$ & $-0,05703^{\star *}$ \\
\hline Espírito Santo & $0,12015^{\star \star}$ & 8,60307 & $-0,04665^{\star *}$ & $-0,46344^{\star *}$ \\
\hline Minas Gerais & $0,05409 * *$ & $0,21299 * *$ & $0,00976^{* *}$ & $-0,42335^{\star *}$ \\
\hline Área metropolitana & $0,08196^{\star *}$ & $0,08673^{\star *}$ & $0,14557^{* *}$ & $0,19583^{* *}$ \\
\hline Rendimento do não-trabalho & $-0,00010^{\star *}$ & $-0,00017^{\star *}$ & $-0,00007^{\star \star}$ & $0,00008^{\star *}$ \\
\hline Constante & $1,07101^{* *}$ & $1,61233^{\star *}$ & $1,04233^{* *}$ & $1,28010^{\star *}$ \\
\hline \multicolumn{5}{|l|}{ Salário/hora } \\
\hline Anos de estudo & $0,04747^{\star *}$ & $0,03211^{\star *}$ & $0,05884 * *$ & $0,04653^{* *}$ \\
\hline Experiência & $0,03370^{* *}$ & $0,03099 * *$ & $0,02820 * *$ & $0,01272^{* *}$ \\
\hline Exp. ao quadrado & $-0,00037^{* *}$ & $-0,00037^{* *}$ & $-0,00026^{\star *}$ & $-0,00010^{\star *}$ \\
\hline Escolaridade X exp. & $0,00081^{* *}$ & $0,00078^{\star *}$ & $0,00027^{* *}$ & $0,00040^{* *}$ \\
\hline Cor & $-0,14223^{\star *}$ & $-0,10904 * *$ & $-0,10219^{\star \star}$ & $-0,11921^{\star *}$ \\
\hline Ocupação 2 & $0,15804^{\star *}$ & $0,22239 * *$ & $0,05552^{* *}$ & $0,10594^{\star *}$ \\
\hline Ocupação 3 & $-0,17929 * *$ & $-0,27376^{\star *}$ & $-0,25050 * *$ & $-0,21939$ ** \\
\hline Ocupação 4 & $-0,50658^{* *}$ & $-0,63680^{\star *}$ & $-0,49994^{\star *}$ & $-0,49507^{\star *}$ \\
\hline Ocupação 5 & $-0,75351 * \star$ & $-0,86181 * \star$ & $-0,62988^{\star \star}$ & $-0,65601$ ** \\
\hline Ocupação 6 & $-0,58843^{\star *}$ & $-0,78838^{\star *}$ & $-0,62157^{\star \star *}$ & $-0,69822^{\star *}$ \\
\hline Ocupação 8 & $-0,51155^{\star *}$ & $-0,63051 * *$ & $-0,79457^{\star \star *}$ & $-0,73872^{\star *}$ \\
\hline Ocupação 9 & $-0,12759^{\star *}$ & $-0,17843^{\star \star}$ & $0,18496^{\star *}$ & $0,36957^{\star *}$ \\
\hline Funcionário público & $0,16143^{* *}$ & $0,19048^{\star *}$ & $0,12047^{* \star}$ & $0,12028^{* *}$ \\
\hline Empregado sem carteira & $-0,25579 * *$ & $-0,29659 * *$ & $-0,16725^{\star \star}$ & $-0,14775^{\star \star}$ \\
\hline Trab. doméstico com carteira & $-0,02273^{* *}$ & $-0,18496^{\star *}$ & $-0,12406^{\star *}$ & $0,00863^{* *}$ \\
\hline Trab. doméstico sem carteira & $-0,32353^{\star *}$ & $-0,41717^{\star *}$ & $-0,15892^{\star *}$ & $-0,04623^{\star *}$ \\
\hline Conta própria & $-0,08256^{\star *}$ & $-0,15114^{\star *}$ & $-0,00289^{\star \star}$ & $-0,05429 * \star$ \\
\hline Empregador & $0,16736^{\star *}$ & $-0,04516^{\star *}$ & $0,25460 * *$ & $0,11770^{* *}$ \\
\hline Rio de Janeiro & $-0,15676^{\star *}$ & $-0,08431 * *$ & $-0,10127^{* *}$ & $-0,03648^{* *}$ \\
\hline Espírito Santo & $-0,12893^{* *}$ & $-0,12671 * *$ & $-0,12265^{\star *}$ & $-0,05370^{* *}$ \\
\hline Minas Gerais & $-0,17786^{\star \star}$ & $-0,14688^{\star * *}$ & $-0,21663^{\star *}$ & $-0,13523^{* *}$ \\
\hline Área metropolitana & 0,12148 ** & $0,05936^{\star *}$ & $0,19625^{\star *}$ & $0,12774^{* *}$ \\
\hline Constante & $0,77021 * *$ & $1,139323^{\star *}$ & $0,554683^{* *}$ & $0,9763364^{* *}$ \\
\hline № observações & 10.000 .000 & 3.458 .690 & 8.034 .514 & 2.738 .792 \\
\hline № obs. censuradas & 70.914 & 25.514 & 217.508 & 65.580 \\
\hline Wald chi2 (22) & 9.210 .000 & 2.390 .000 & 7.360 .000 & 1.510 .000 \\
\hline Prob > chi2 & 0,0000 & 0,0000 & 0,0000 & 0,0000 \\
\hline
\end{tabular}

** Significância a $5 \%$. 


\section{Resumen}

Diferencia de salarios entre hombres y mujeres según la condición de migración

Este trabajo analiza la diferencia salarial por sexo, según la condición de migración de la población. Por medio del cálculo del índice de disimilaridad de Duncan y de la descomposición de Oaxaca para los salarios de hombres y mujeres migrantes y no-migrantes, se encontraron situaciones diferenciadas para la Región Sudeste y el resto del país. Los resultados muestran que la elevada diferencia salarial entre sexo verificada en la población migrante residente fuera de la Región Sudeste se mantiene, debido a la diferente valorización en el mercado de trabajo del lugar de destino de los atributos masculinos con respecto a los femeninos. Por otro lado, en el caso del Sudeste, la menor diferencia salarial constatada entre hombres y mujeres migrantes se debe más a las características específicas de las trabajadoras que a la valorización diferenciada en el mercado de trabajo.

Palabras-clave: Diferencia de salario por sexo. Migración. Segregación. Índice de disimilaridad. Descomposición Oaxaca-Blinder.

\section{Abstract \\ Wage differences between men and women according to condition of migration}

This article analyzes wage differences by gender, as per condition of migration of the population. By calculating Duncan's dissimilarity index and the Oaxaca decomposition for wages of male and female migrants and non-migrants, great differences were noted between the southeastern region of Brazil and the rest of the country. The findings show that the great wage differences between genders detected in the migrant population living outside the southeastern region is due to the different valuation on the labor market of male attributes vis-a-vis female. But in the southeast the narrower wage difference between men and women migrants was seen as being due more to the specific characteristics of the workers than to different valuation on the labor market.

Keywords: Wage differences by gender. Migration. Segregation. Dissimilarity Index. OaxacaBlinder decomposition. 